\title{
Sopecal The Effect of Naphthalene-Based Additives on the Kinetics of Tin Electrodeposition on Boron-Doped Diamond Electrodes
}

\author{
Diana Aranzales, ${ }^{[a]}$ Jacques H. O. J. Wijenberg, ${ }^{[b]}$ and Marc T. M. Koper ${ }^{*[a]}$
}

The effect of naphthalene-based additives: naphthalene (NPT), naphthalenesulfonate (NPTS) and hydroxynaphthalenesulfonate (HNPTS) on the kinetics of tin electrodeposition on a borondoped diamond (BDD) electrode has been studied by means of chronoamperometry and scanning electron microscopy (SEM). Potentiostatic current transients in the absence and the presence of naphthalene-based additives are analyzed by using the Scharifker-Hills model. A strong decrease of the kinetics of tin nucleation on BDD was observed in the presence of naphthalene-based additives, NPT showing the smallest effect and HNPTS showing the largest effect. From the long-term Cottrell behavior of the transients, similar values of tin(II) diffusion coefficients were obtained for all additives, suggesting that there is no complexation of Sn(II) by the additives and that the charge-transfer kinetics itself is not substantially influenced by the presence of the additives. In the absence of additives, tin deposition on BDD displays a progressive nucleation and growth mechanism at the least negative potentials, switching to instantaneous nucleation and growth at more negative potential. In the presence of NPTS and HNPTS, progressive nucleation and growth transients are observed. The growth mode results are confirmed by the tin features observed in the scanning electron micrographs. In conclusion, NPT, NPTS and HNPTS mainly decrease the rate of the nucleation of tin deposition, most likely by blocking or reducing access to active nucleation sites. In comparison, ethoxylated $\alpha$-napthalenesulfonic acid (ENSA, a commonly used additive in the tin plating industry) inhibits tin deposition process on BDD even more strongly. These observations show a striking similarity to our previous study of tin deposition on gold electrodes.

\section{Introduction}

Tin electrodeposition is a low-cost and versatile process, widely used in multiple sectors of industry such as automobile, welding in electronics manufacturing, corrosion protection, in the packaging industry and solar power generation. ${ }^{[1,2]}$ During the last years, new applications for tin plating in electronics and manufacturing have been developed, and since then, new challenges in the micro and nanotechnology of the process have emerged. The production of high-quality tin coatings requires the addition of organic compounds in the electroplating baths, in order to obtain the desired chemical and physical properties of the metal deposits. Determining the role of these additives in the mechanism and kinetics of the process provides the possibility of tailoring the properties of tin and other metals coatings, and it will facilitate the enhancement of

\footnotetext{
[a] Dr. D. Aranzales, Prof. M. T. M. Koper

Leiden Institute of Chemistry

Leiden University

P.O. Box 9502, 2300 RA Leiden, The Netherlands

E-mail:m.koper@chem.leidenuniv.nl

[b] Dr. J. H. O. J. Wijenberg

Tata Steel, Research \& Development

IJmuiden Technology Centre

P.O. Box 10.000, 1970 CA IJmuiden, The Netherlands

Supporting information for this article is available on the WWW under https://doi.org/10.1002/celc.202100034

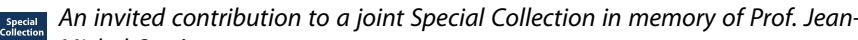
Michel Savéant
}

the deposition process and the extension of the tin and other metal coating applications.

Tin electrodeposition has been studied on multiple substrates, metallic and non-metallic, such as gold, platinum, ${ }^{[3-12]}$ copper, $^{[4,7,9-11,16-18]}$ mercury, ${ }_{1}^{[4]}$ iron, $^{[5-11]}$ steel, $^{[12,13]}$ aluminum, ${ }^{[4]}$ glassy carbon, ${ }^{[5]}$ and vitreous carbon. ${ }^{[6]}$ Furthermore, the effect of additives (mainly organic molecules) on the tin electrodeposition process has also been investigated. Previous studies reported the effect of molecules such as sdodecylmercaptobenzimidazole ${ }^{[7]}$ perfluorinated cationic surfactants ${ }^{[8]}$ hydroquinone, ${ }^{[9]}$ benzyl compounds, ${ }^{[10]}$ sorbitol, ${ }^{[11]}$ gluconate ${ }^{\left[{ }^{[6]}\right.}$ phenol sulfonic acid and ethoxylated $\alpha$-naphthalenesulfonic acid (ENSA-6). ${ }^{[4]}$ Literature has mainly focused on the effect of the additives on the morphological and compositional characteristics of the tin deposits, and ascribed the effects of the additives to the local mass transport of $\mathrm{Sn}$ (II) ions, ${ }^{[12]}$ incorporation of organic molecules, and/or to the effect of the concurrent hydrogen evolution reaction. ${ }^{[9]}$ Up to now, only few studies have investigated the effect of additives on the early stages of the nucleation and growth of the tin deposition process. ${ }^{[13]}$

In our previous work on tin electrodeposition, ${ }^{[14]}$ we chose gold as a model substrate and studied a family of naphthalenebased additives. By using in-situ spectroscopy and density functional theory studies, we characterized the adsorption behavior of naphthalene-based additives as well as ethoxylated $\alpha$-naphthalenesulfonic acid (ENSA-6), a commonly used additive in the tin electroplating industry, on well-defined gold surfaces, 
and discussed their correlation with the tin electrodeposition process. ${ }^{[15]}$

Following our previous work, in this paper we focus on studying the kinetics of tin nucleation and growth. A change in the substrate was required to avoid the contribution of surface alloying in the process. Therefore, we study here the effect of naphthalene-based derivatives, naphthalene (NPT), naphthalenesulfonate (NPTS), and hydroxynaphthalenesulfonate (HNPTS), on the kinetics of the nucleation and growth of tin electrodeposition on a boron doped diamond electrode (BDD). Boron doped diamond has been considered as highly suitable to study metal deposition, ${ }^{[16-19]}$ due to its high stability, reproducibility, and flat surface with height variation of $\sim 5 \mathrm{~nm}$ over $25 \mu \mathrm{m}^{2}$ areas. The relatively low defect density is expected to lead to a low nucleation rate. This facilitates nucleation and growth measurements by electrochemical transient experiments and in-situ microscopic techniques. ${ }^{[16]}$

\section{Results and Discussion}

\subsection{Chronoamperometric Transients}

Figure 1 shows the cyclic voltammogram for tin electrodeposition and electro-dissolution on a BDD electrode (under static conditions, i.e., no rotation). The voltammogram exhibits a broad cathodic wave with a peak at $-0.266 \mathrm{~V}$, and a sharp anodic peak at $-0.156 \mathrm{~V}$, characteristic of $\mathrm{Sn}(\mathrm{II})$ reduction and $\mathrm{Sn}(0)$ oxidation, respectively. The cyclic voltammogram was used as a reference to choose the potential region to record the current transients, as indicated by the red lines, from -0.220 to -0.460 V. Figure S1 in the Supporting Information compares the $\mathrm{CV}$ to the blank of the BDD electrode; these curves also show that no significant hydrogen evolution (proton reduction) is taking place in the studied potential window. Although

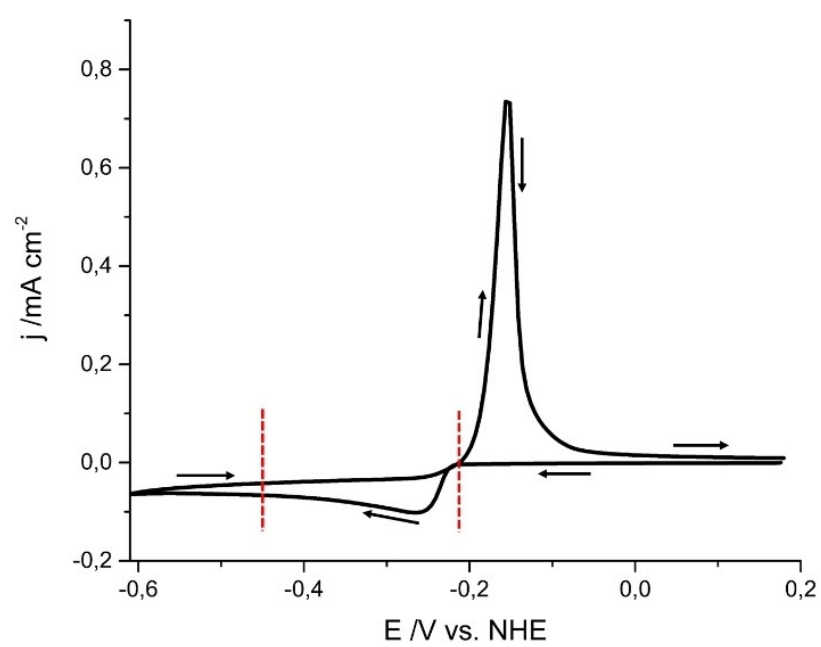

Figure 1. Cyclic voltammogram of tin electrodeposition on a boron doped diamond surface in $0.1 \mathrm{M} \mathrm{H}_{2} \mathrm{SO}_{4}$ and $0.5 \mathrm{mM} \mathrm{SnSO}_{4}$. $\mathrm{CV}$ recorded between -0.61 to $0.19 \mathrm{~V}$ at $30 \mathrm{mV} \mathrm{s}^{-1}$. Red-dashed lines indicate the potential region used for measuring the current transients, arrows indicate the potential scan direction. previous studies have discussed the concurrent proton reduction on tin during its electrodeposition process on different substrates, ${ }^{[20-24]}$ copper, $^{[22-24]}$ glassy carbon $^{[23]}$ and steel, ${ }^{[21]}$ with an interpretation of the chronoamperometric data according to the model proposed by Palomar-Pardavé et al., ${ }^{[20]}$ proton reduction on $\mathrm{Sn}$ does not happen below $-0.5 \mathrm{~V}^{[14]}$ and we believe that we can safely neglect proton reduction in the transients presented below. Indeed, $\mathrm{Sn}$ is a poor HER catalyst due to the weakness of $\mathrm{Sn}-\mathrm{H}$ bond. ${ }^{[25,26]}$

Figure 2 presents the recorded current transients for tin electrodeposition without additives; transients show rising currents related with the nucleation and growth processes, followed by a current decay caused by the overlap of the growing nuclei and at longer times by mass transport limitations. The recorded current transients exhibit shorter peak times and higher current maxima with increasingly negative potential. ${ }^{[16]}$ This behavior is usual for nucleation and growth processes, provided the substrate is not being strongly modified over the range of applied potentials. ${ }^{[27]}$

The current transients are analyzed by comparison to the well-established Scharifker-Hills (SH) model. ${ }^{[28]}$ The SH model considers nuclei of hemispherical shape, whose growth is controlled by three-dimensional diffusion. Two limiting cases of nucleation and growth are described by the model: instantaneous and progressive.

The nucleation rate is described by Equation (1):

$N(t)=N_{o}\left(1-e^{-A t}\right)$

where $N$ is the number of nuclei, $N_{0}$ the number of nucleation sites, and $A$ the nucleation rate constant. For instantaneous nucleation, all nuclei are formed at once when applying the step potential, so that $A t \gg 1$ and therefore $N(t)=N_{o}$. The

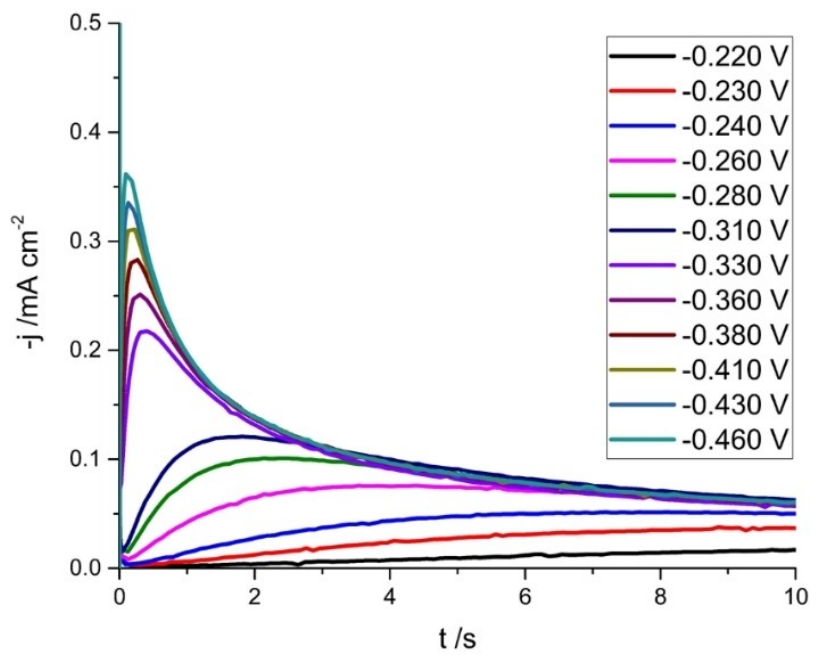

Figure 2. Current transients of tin electrodeposition on a boron doped diamond surface in $0.1 \mathrm{M} \mathrm{H}_{2} \mathrm{SO}_{4}$ and $0.5 \mathrm{mM} \mathrm{SnSO}_{4}$. Transients were recorded between -0.220 to $-0.460 \mathrm{~V}$. For each transient, the respective potential was applied during $1 \mathrm{~min}$, and it was followed by applying $0.14 \mathrm{~V}$ during 3 minutes to dissolve the deposit. Dissolution of the tin deposit was carried out before applying each respective potential. 
current-time transient for instantaneous nucleation and growth is given by Equation (2):

$j(t)=\frac{z F D^{1 / 2} c}{\pi^{1 / 2} t^{1 / 2}}\left[1-\exp \left(-N_{o} \pi \kappa D t\right)\right]$

where $\kappa=(8 \pi \mathrm{cM} / \rho)^{1 / 2}$, with $\mathrm{c}$ the concentration $\left(\right.$ of $\left.\mathrm{Sn}^{2+}\right), M$ the molar mass, and $\rho$ the molar density.

For progressive nucleation and growth, nuclei are gradually formed after applying the step potential, so that $A t \ll 1$ and therefore $N(t)=A N_{o} t$. The current-time transient for progressive nucleation and growth is given by Equation (3):

$j(t)=\frac{z F D^{1 / 2} c}{\pi^{1 / 2} t^{1 / 2}}\left[1-\exp \left(-\frac{2}{3} A N_{o} \pi \kappa D t^{2}\right)\right]$

By plotting current transients in normalized coordinates, $\left(\frac{j}{j_{\max }}\right)^{2}$ vs $\frac{t}{t_{\max }}$, we avoid the use of the system-specific parameters $\left(c, M, \rho, A N_{0}, N_{0}\right.$ ) in comparing the experimental transients with the two limiting cases. ${ }^{[28]}$ The associated expressions for instantaneous and progressive nucleation are described by Equations (4) and (5), ${ }^{[28,29]}$ respectively:

$\frac{j^{2}}{j^{2} \max }=1.9542\left(\frac{t}{t_{\max }}\right)^{-1}\left[1-\exp \left(-1.2564 \frac{t}{t_{\max }}\right)\right]^{2}$

with $j_{\max }=0.6382 z F D c(k N)^{1 / 2}$ and $t_{\max }=1.2564 / N \pi k D$ for instantaneous nucleation

$\frac{j^{2}}{j_{\max }^{2}}=1.2254\left(\frac{t}{t_{\max }}\right)^{-1}\left[1-\exp \left(-2.3367 \frac{t^{2}}{t^{2} \text { max }}\right)\right]^{2}$

with $\quad j_{\max }=0.4959 z F D^{3 / 4} c\left(k^{2} N_{0}\right)^{1 / 4}$

and

$t_{\max }=\left(3.505 / a N_{0} \pi k D\right)^{1 / 2}$ for progressive nucleation.

The Scharifker-Hills model is based on a number of simplifying assumptions that need to be considered when comparing experimental transients to $\mathrm{SH}$ predictions. The $\mathrm{SH}$ model examines two nucleation limiting cases: progressive and instantaneous. In the instantaneous case, all the nuclei should virtually form at the same time, which is strictly speaking not possible, since a certain period of time is still required; one could also be view this as progressive nucleation with a very high nucleation rate. ${ }^{[30]}$ As mentioned, nuclei in the $\mathrm{SH}$ model are hemispherical, and hence their growth rate is dictated by the hemispherical geometry. This assumption generates a situation where the growth and diffusion of the depositing material extends to the bulk; such a situation between $2 \mathrm{D}$ and 3D diffusion has been solved approximately by $\mathrm{SH}$ using Avrami's theorem. ${ }^{[35]}$ Further improvements on describing and analyzing this situation have been proposed by Scharifker and Mostany $^{[31]}$ and by Sluyters-Rehbach et al. ${ }^{[37]}$ An extensive discussion on this issue can be found in the review by Hyde and Compton. ${ }^{[38]}$ The nucleation sites in the $\mathrm{SH}$ model are distributed randomly. In reality, nucleation sites are often associated with defects sites in the substrate (see also our SEM results below), which are not distributed randomly. Finally, the growth of nuclei in the SH model is purely diffusion controlled, whereas in reality, the kinetics of metal deposition may contribute to the growth rate, especially at low overpotential. Approximate models for growing nuclei under mixed kinetic and diffusion control have been derived by Fletcher ${ }^{[33]}$ and Milchev. ${ }^{[34]}$ Ross et al. ${ }^{[35]}$ have compared the predictions of the $\mathrm{SH}$ model to real-time imaging of growing copper clusters on a gold electrode using a small liquid transmission electron microscopy cell. They showed that the $\mathrm{SH}$ model may grossly underestimate the actual nucleus density, and ascribe this to the importance of surface adatom formation and surface diffusion on the gold during the initial stage of the process.

Figure 3 shows the normalized current transients for tin deposition on boron doped diamond from low to high overpotentials compared to the instantaneous and progressive nucleation limiting cases. For a potential of $-0.260 \mathrm{~V}$, it is seen that at short times the experimental transient curve satisfactorily overlaps with the progressive nucleation mechanism. However, at longer times the experimental curve deviates from the progressive nucleation mechanism. Furthermore, at higher overpotentials and shorter times, the experimental current transients do not satisfactorily fit with neither the progressive nor the instantaneous nucleation mechanisms. However, at longer times, the experimental curves fit better with the instantaneous mechanism. Hyde et al. have also noted that a (least-squares) fitting of experimental transients to the $\mathrm{SH}$ model is difficult because the fit is never perfect and a range of $A$ and $N_{0}$ values give similarly shaped curves. ${ }^{[38]}$ It is likely that the deviations between experiment and theory are related to the simplifying assumptions mentioned in the previous paragraph (we note that double-layer charging happens at very short times and cannot explain the deviation between the $\mathrm{SH}$ model and the experimental transients). Because of this lack of perfect agreement between the $\mathrm{SH}$ expressions and the experimental transients (see also Figure S2), we use the $\mathrm{SH}$

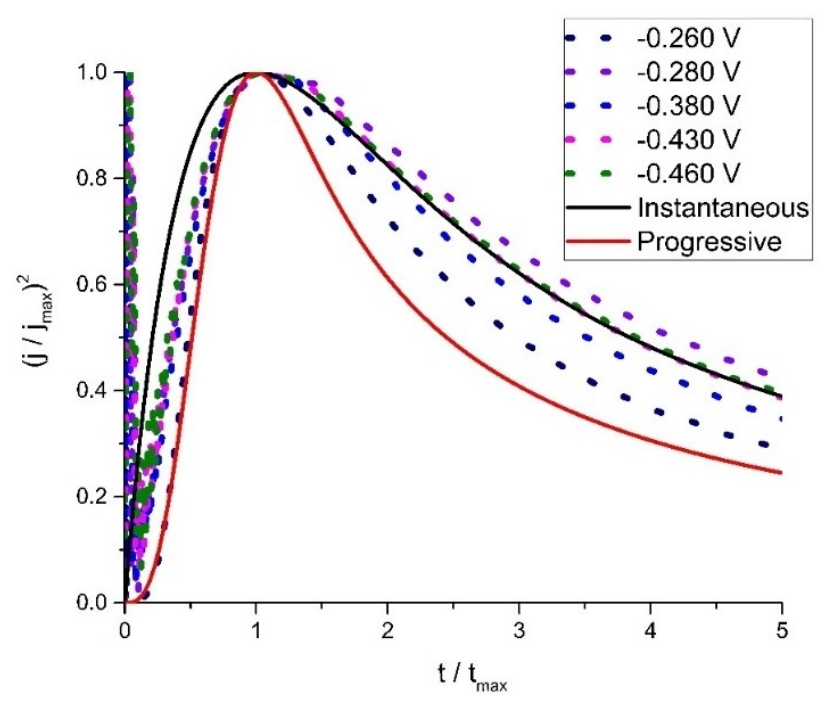

Figure 3. Normalized current transients calculated with $\mathrm{SH}$ model for the limiting cases (solid lines) compared with the normalized experimental transients (dotted lines). Experimental transients were recorded in $0.1 \mathrm{M}$ $\mathrm{H}_{2} \mathrm{SO}_{4}$ and $0.5 \mathrm{mM} \mathrm{SnSO}_{4}$. 
model only in a semi-quantitative sense. First of all, from the shape of the transient at short times, we can derive whether the mechanism of nucleation is progressive or instantaneous. For progressive nucleation and growth, the transient should show a positive second derivative $\left(d^{2} j / d t^{2}\right)$ at short times, whereas for instantaneous nucleation growth, the second derivative should be negative. Secondly, from the values for $t_{\text {max }}$, we can estimate values for the nucleation rate $A N_{0}$ and the number of nucleation sites $N_{0}$. One could in principle obtain $A N_{0}$ and $N_{0}$ from fitting the entire transient as well, but given the comparison in Figure 3, we do not think that this adds accuracy to the obtained values. An alternative way to determine these parameters is to fit the initial part of the transient to a general nucleation equation. Sluyters-Rehbach et al. ${ }^{[32]}$ described a general equation of nucleation and diffusion-controlled hemispherical growth, and employed a graphical analysis of the current transients: $\left(j^{2 / 3}\right.$ vs $\left.t\right)$ and $\left(j^{2}\right.$ vs $\left.t\right)$ to check the consistency between the model and the experimental transients and also to determine whether one of the two nucleation limiting cases, vis. instantaneous or progressive, predominates. This offers a more accurate way of determining parameters such as $A$ and $N_{0}$. However, given the high doublelayer current at short times, the values of the parameters $A$ and $N_{0}$ were difficult to extract, and since we were primarily interested in the qualitative behavior of $A$ and $N_{0}$, deriving them from $t_{\max }$ served our purposes well.

Figure 3 also shows the transition from progressive to instantaneous nucleation with increasingly negative potential. This behavior is also indicative that the electrode surface (and the number of nucleation sites) is not changing considerably with potential. In order to confirm the transition from progressive to instantaneous nucleation when increasing the negative potential, the second derivatives of the current transients at less and more negative potentials were calculated. As mentioned, for a progressive nucleation and growth mechanism, one expects a positive second derivative at short times, whereas for instantaneous nucleation, the second derivative should be negative at short times. Figure S3 shows the second derivative (blue dotted line) for the onset of the transient (short times) for various potentials, showing that the transition to instantaneous nucleation and growth happens at a potential of ca. $-0.33 \mathrm{~V}$. Figures $\mathrm{S} 3 \mathrm{c}$ and $\mathrm{S} 3 \mathrm{~d}$ exhibit a high noise level at short times (i.e. $<0.2 \mathrm{~s}$ ) as a consequence of the charge-discharge double layer process. The noise level also increases by calculating the derivative. Both Gomez et al. ${ }^{[36]}$ and Torrent-Burgues et al. ${ }^{[6]}$ have observed a similar transition from progressive to instantaneous nucleation and growth with increasingly negative potential for tin electrodeposition on (vitreous) carbon electrodes.

As mentioned above, estimates of the steady state nucleation rate ${ }^{[37]}\left(A N_{0}\right)$ and the number of nucleation sites $\left(N_{0}\right)$ were estimated from the corresponding expressions of $t_{\max }$, see Equations (4) and (5).

Figure 4 shows the logarithm of the steady state nucleation rate $\left(A N_{0}\right)$ and number of nucleation sites $\left(N_{0}\right)$ plotted versus the applied potential. It is observed that both $A N_{0}$ and $N_{0}$ exhibit an approximately linear increase at potentials below

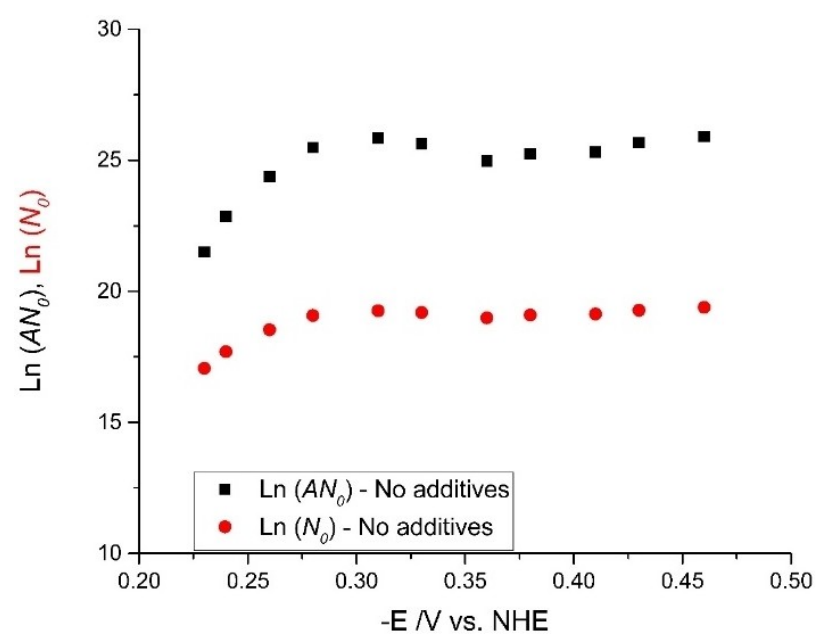

Figure 4. Logarithm of steady state nucleation rate $\left(A N_{o}\right)$ and Logarithm of the number of nucleation sites $\left(N_{0}\right)$ versus applied potential of tin electrodeposition on a boron doped diamond surface in $0.1 \mathrm{M} \mathrm{H}_{2} \mathrm{SO}_{4}$ and $0.5 \mathrm{mM}$ $\mathrm{SnSO}_{4}$. The parameters $N_{0}$ and $A N_{0}$ (black dots) were calculated from the corresponding expressions for $t_{\text {max }}$ Eqs. (4) and (5) (see main text).

$-0.28 \mathrm{~V}$, and remain essentially constant at potentials more negative than $-0.30 \mathrm{~V}$. This transition potential corresponds reasonably well to the transition from progressive to instantaneous nucleation evaluated in Figure S3. Therefore, we consider the $A N_{0}$ data more meaningful for potentials $>-0.3 \mathrm{~V}$ and the $N_{0}$ data for potentials $<-0.3 \mathrm{~V}$. The atomistic theory of nucleation predicts a linear dependence of the logarithm of the steady state nucleation rate $\left(A N_{0}\right)$ on the overpotential at high supersaturation. ${ }^{[38]}$ Figure 4 indeed exhibits a linear dependence of the steady state nucleation rate on the applied potential in the window where the $A N_{0}$ data are meaningful. The data for $E<-0.3 \mathrm{~V}$, where the data for $N_{0}$ is more meaningful, show that $N_{0}$ is essentially constant over a wide potential window.

\subsection{Effect of Naphthalene-Based Additives on Kinetics of Tin Electrodeposition on BDD}

In order to study the effect of naphthalene-based additives on the kinetics of tin electrodeposition on a boron doped diamond electrode, current transients of tin electrodeposition were recorded in the presence of three different additives: NPT, NPTS and HNPTS. Figure $5 \mathrm{a}, 5 \mathrm{~b}$ and $5 \mathrm{c}$ show current transients recorded at highly negative potential $(-0.460 \mathrm{~V})$ in the presence of different concentrations of NPT, NPTS and HNPTS, respectively, and Figure $5 d$ shows the comparison of the different naphthalene-based additives.

Figure 5a shows transients in the absence and presence of NPT at different concentrations. Transients exhibit an increase of $t_{\max }$ and decrease of $i_{\max }$, ascribed to a decrease of the nucleation rate of tin deposition on BDD. The transients do not show a remarkable dependence on the NPT concentration which we attribute to the low solubility of NPT molecules in the aqueous electrolyte, leading to the same bulk concentration and thereby limiting the amount of NPT available that can be 

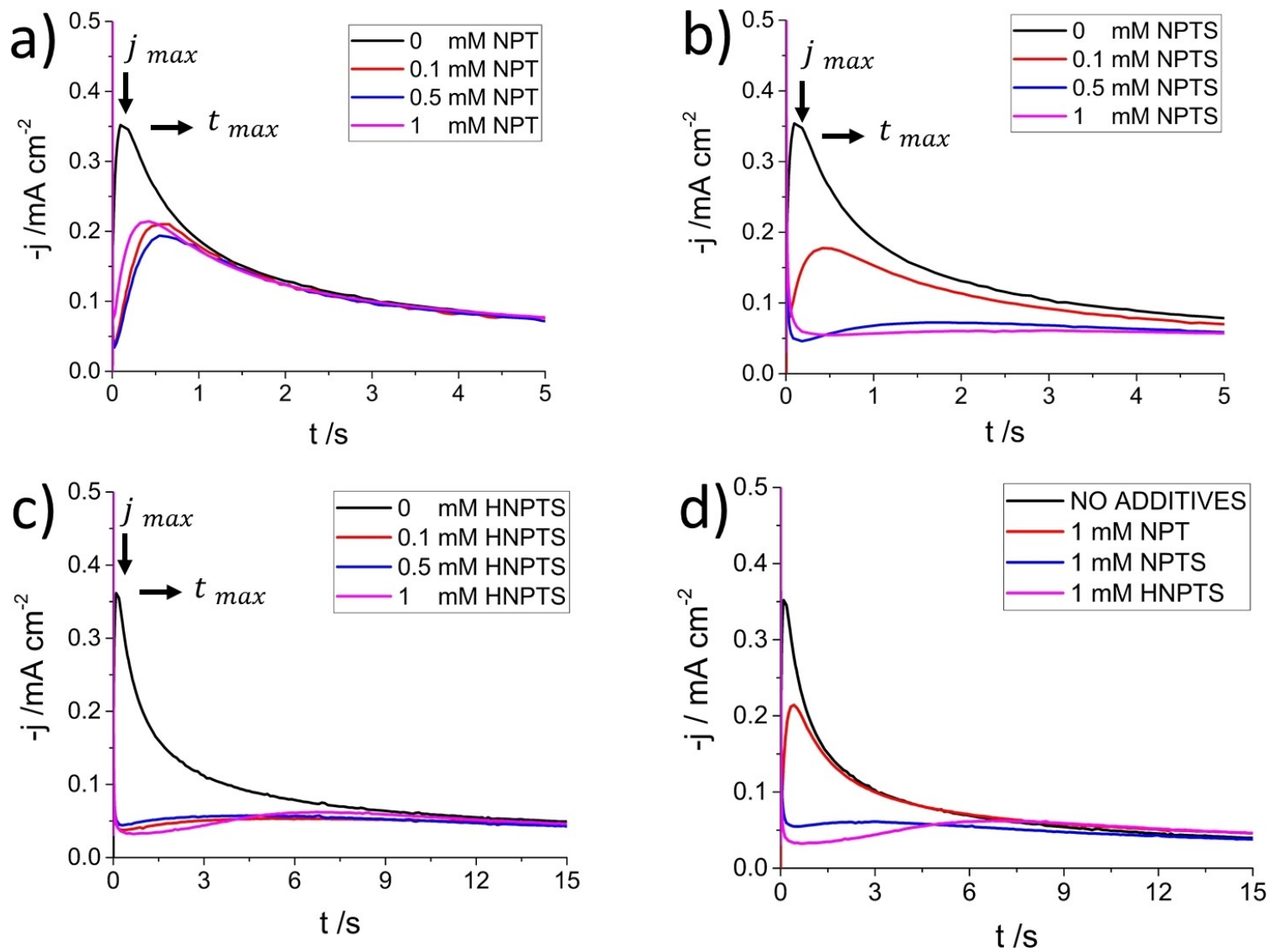

Figure 5. Current transients recorded at more negative potential ( $-0.460 \mathrm{~V})$ of tin electrodeposition on a boron doped diamond surface in $0.1 \mathrm{M} \mathrm{H}_{2} \mathrm{SO}_{4}$, $0.5 \mathrm{mM} \mathrm{SnSO}_{4}$ and different naphthalene-based concentrations: a) NPT, b) NPTS, and c) HNPTS. d) Comparison of transients in the absence and presence of $1 \mathrm{mM}$ naphthalene-based additives.

adsorbed on BDD surface. Furthermore, current transients in the absence and in the presence of different NPT concentrations overlap after about 1.5 seconds.

Figure $5 \mathrm{~b}$ shows transients in the absence and presence of NPTS. Parameters $t_{\max }$ and $i_{\max }$ increase and decrease, respectively, with increasing NPTS concentration. This change is also ascribed to a decrease in the nucleation kinetics of tin deposition. The transient in the presence of $1 \mathrm{mM}$ of NPTS looks almost flat in comparison to the other transients. Figure $5 \mathrm{c}$ presents the transients in the absence and presence of HNPTS; transients exhibit a much stronger decrease in $i_{\max }$ and increase in $t_{\max }$ compared to the transients in the presence of NPT and NPTS. Additionally, Figure $5 \mathrm{~d}$ compares the different additives in a single figure, clearly illustrating the evolution of the transient as a function of the additive.

For long deposition times, the $\mathrm{SH}$ model assumes the growth of the deposit to be completely diffusion limited. Therefore, tin (II) diffusion coefficients $\left(D_{\mathrm{Sn}^{2+}}\right)$ can be calculated in the presence of different concentrations of naphthalenebased additives by fitting the transient to the Cottrell equation. The results are summarized in Table S1 in the Supporting Information. The equation was applied for the transients at $-0.460 \mathrm{~V}$, and at times longer than $20 \mathrm{~s}$ to avoid contributions from nucleation kinetics. A plot of $\mathrm{j} v \mathrm{v}$. $\mathrm{t}^{-1 / 2}$ yields a straight line in all cases. The calculated value of tin (II) diffusion coefficient $\left(D_{\mathrm{Sn}^{2+}}\right)$ in the absence of naphthalene-based additives is $7.7 \pm$ $0.2 \times 10^{-6} \mathrm{~cm}^{2} \mathrm{~s}^{-1}$, which is in accordance with previously determined values. ${ }^{[2,39]}$ The values in the presence of $1 \mathrm{mM}$ of NPT, NPTS and HNPTS are $6.8 \times 10^{-6}, 7.0 \times 10^{-6}$ and $7.3 \times$ $10^{-6} \mathrm{~cm}^{2} \mathrm{~s}^{-1}$ respectively, all in reasonable agreement. In the presence of different concentrations of HNPTS, the calculated tin (II) diffusion coefficient $\left(D_{\mathrm{Sn}^{2+}}\right)$ also does not change considerably. We do not consider these differences between the diffusion coefficients to be substantial. Furthermore, when tin(II) diffusion coefficients $\left(D_{\mathrm{Sn}^{2+}}\right)$ are calculated from transients obtained at less negative potentials in the presence of the naphthalene-based additives, no significant differences were observed either, see Table S2. These results suggest that naphthalene-based additives do not affect the Sn(II) transport to the electrode surface, and also do not have a strong contribution on the kinetics of the growth of the tin nuclei. Therefore, the naphthalene-based additives primarily affect the nucleation rate. Plots of $j$ vs $t^{-0.5}$ of current transients recorded at times longer than $20 \mathrm{~s}$ and different applied potentials, in the absence and the presence of naphthalene-based additives are shown in Figure S4.

Figure 6 shows the onset of the current transients recorded in the absence and presence of naphthalene-based additives. 


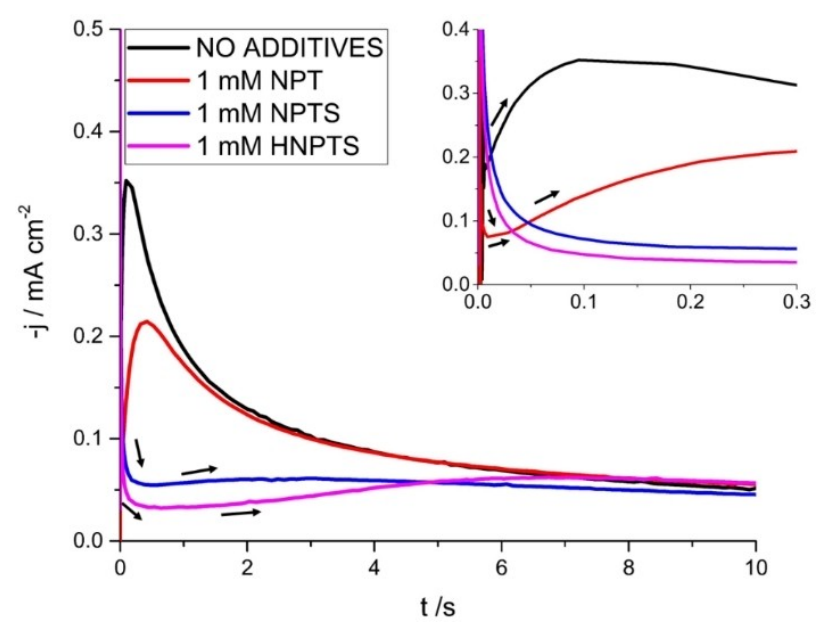

Figure 6. Onset of the current transients recorded in $0.1 \mathrm{M} \mathrm{H}_{2} \mathrm{SO}_{4}, 0.5 \mathrm{mM}$ $\mathrm{SnSO}_{4}$ at high negative potentials $E=-0.460 \mathrm{~V}$, in the absence and presence of $1 \mathrm{mM}$ of NPT, NPTS, and HNPTS at $-0.460 \mathrm{~V}$.

The onset of the current transients in the presence of NPTS and HNPTS clearly show progressive nucleation behavior, where current gradually increases when new nuclei originate. The black arrows indicate the increasing growth of the current typical for progressive nucleation. On the other hand, the onset of the transient in the presence of NPT (Inset of Figure 6) is more characteristic of instantaneous nucleation. See analysis of the second derivative for NPT, NPTS and HNPTS in the Figure S5. The normalized current transients calculated with SH model for the limiting cases in the presence of naphthalenebased additives are also shown in Figure S6. Figure S7 shows the approximate $A N_{0}$ and $N_{0}$ extracted from the transients, confirming that the nucleation rate and/or density decrease in the order NPT, NPTS and HNPTS.

\subsection{Scanning Electron Microscopy}

Scanning electron micrographs were recorded to image the morphology of the tin deposits on BDD in the absence and presence of naphthalene-based additives.

Figure $7 \mathrm{a}$ and $7 \mathrm{~b}$ shows the BDD surface before the tin deposition. Surface defects such as cracks, holes and grain boundaries are visible. Large flat areas of about $\sim 1 \mu \mathrm{m}^{2}$ are also seen. The BDD surface in general exhibits lighter and darker zones which correlates with zones of lower and higher conductivity. ${ }^{[16]}$ By scanning large enough areas, both types of surfaces can be observed in a single image. ${ }^{[16]}$ Images reported here are representative of several images taken over the BBD electrode surface.

Figure $7 c$ and $7 d$ show tin crystallites on BDD surface, obtained in the absence of surfactants by holding the potential at $-0.266 \mathrm{~V}$ for $10 \mathrm{~s}$ at which nucleation and early growth happened, after which the potential was stepped back to $-0.230 \mathrm{~V}$ during $60 \mathrm{~s}$, at which potential the nuclei were grown further. Figures $8 \mathrm{c}$ and $8 \mathrm{~d}$ show how crystallites cluster together at or near the darker defect areas of higher conductivity. The size of the crystallites is approximately $\sim 50 \mathrm{~nm}$ diameter and does not change substantially over the electrode surface, as expected for an instantaneous nucleation mode. Also, nucleation is clearly not random, as assumed in the $\mathrm{SH}$ model.

Figure 8a presents the tin deposits on BDD in the absence of naphthalene-based additives. Unlike tin deposits grown in the absence of additives, tin electrodeposited in the presence

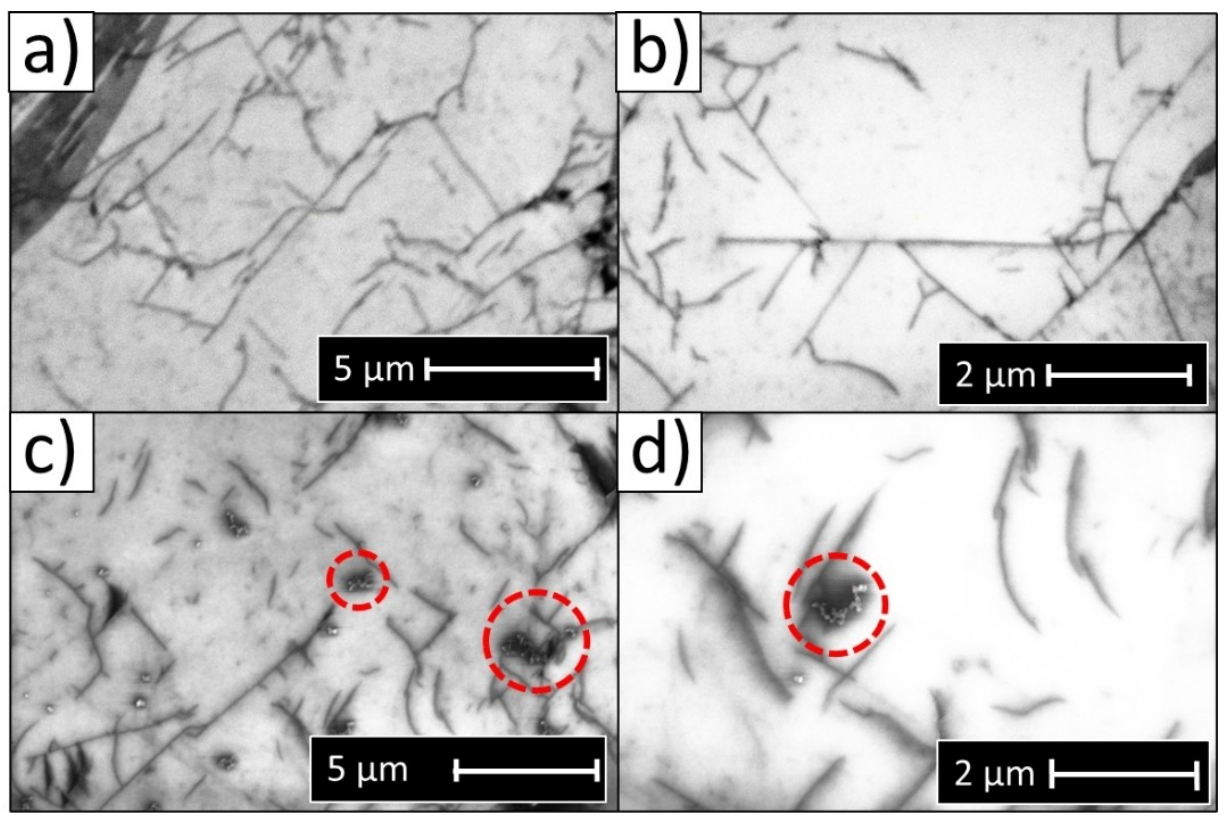

Figure 7. Scanning electron micrographs of $\mathrm{BDD}$ surface before tin deposition $(\mathrm{a}, \mathrm{b})$ and after tin deposition (c, d). Deposition was performed in $0.1 \mathrm{M}_{2} \mathrm{SO}_{4}$ and $0.5 \mathrm{mM} \mathrm{SnSO}_{4}$. Potential was held at $-0.266 \mathrm{~V}$ for $10 \mathrm{~s}$ where nucleation and early growth happened, subsequently the potential was held at $-0.230 \mathrm{~V}$ during $60 \mathrm{~s}$ where the nuclei were grown. 


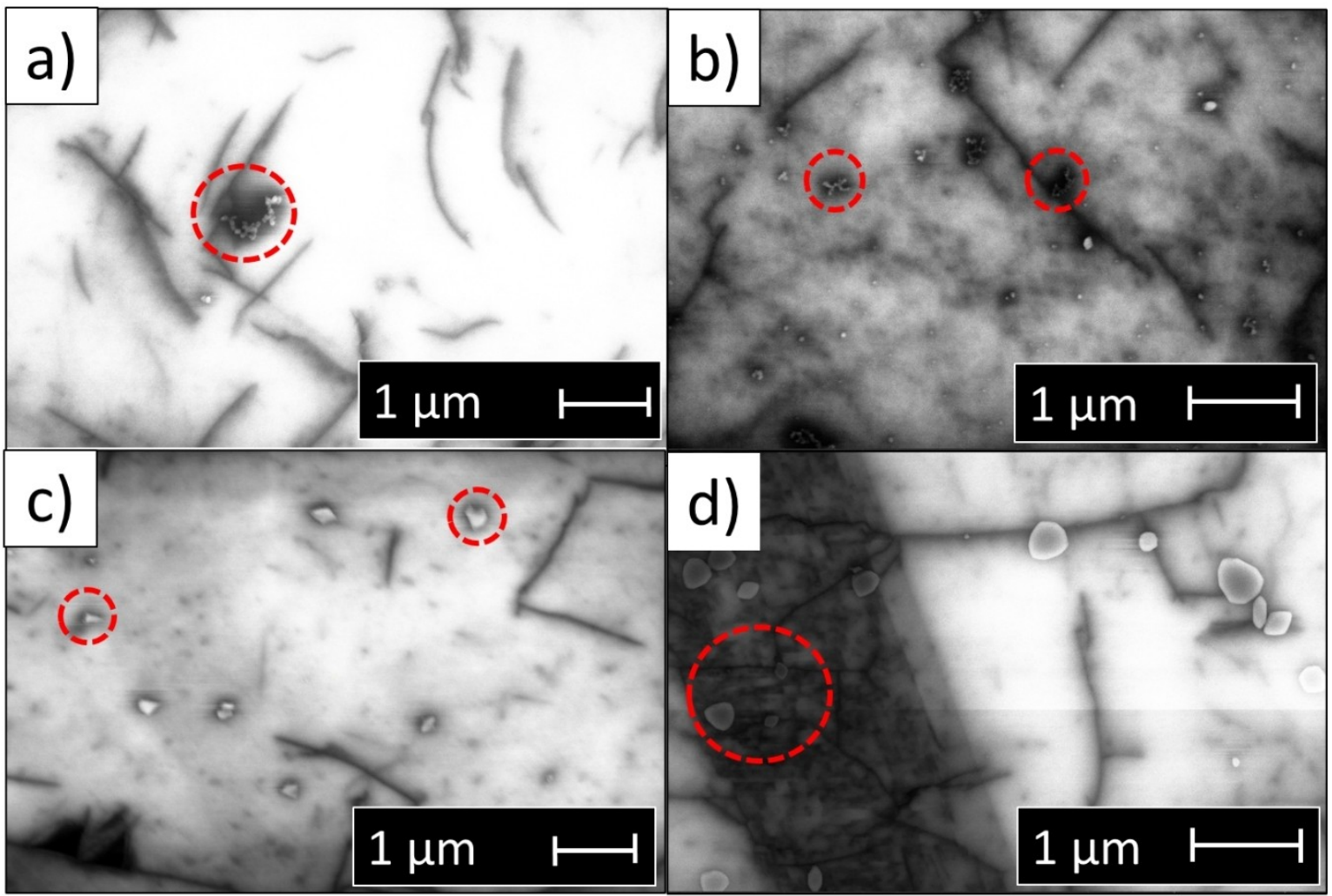

Figure 8. Scanning electron micrographs of tin electrodeposited on a boron doped diamond surface in $0.1 \mathrm{M} \mathrm{H}_{2} \mathrm{SO}_{4}$ and $0.5 \mathrm{mM} \mathrm{SnSO}$ : a) in the absence of naphthalene-based additives, b) in the presence of $1 \mathrm{mM}$ of NPT, c) $1 \mathrm{mM} \mathrm{NPTS}$, d) $1 \mathrm{mM}$ HNPTS. Potential was held at $-0.266 \mathrm{~V}$ for $10 \mathrm{~s}$ where nucleation and early growth happened, subsequently the potential was held at $-0.230 \mathrm{~V}$ during $60 \mathrm{~s}$ where the nuclei were grown.

of NPT on BDD (Figure 8b) exhibits crystallites over the entire surface, not only near the surface defects but also on the large flat areas. Nonetheless, tin deposition is still preferred around the defects, where clusters of crystallites are seen mainly on the cracks and holes. Additionally, crystallites do not exhibit noticeable changes in their size, which is in agreement with instantaneous nucleation mode (See Figure S8). Figure 8c shows the tin deposit grown in the presence of NPTS, tin crystallites are visible near the surface defects and on the large flat areas; crystallites seem to have a specific shape and exhibit a higher distribution, lower density and bigger sizes $(\sim 100 \mathrm{~nm})$ than in the absence and presence of NPT, in accordance with progressive nucleation mode.

Tin deposits grown in the presence of HNPTS are shown in Figure 8d. Tin crystallites grow mainly near the defects; crystallites exhibit a larger size distribution $(\sim 100$ to $\sim 500 \mathrm{~nm})$ which indicates that they were not formed at the same time, i.e., the progressive nucleation mode is operative.

Finally, the effect of ethoxylated $\alpha$-napthalenesulfonic acid (ENSA), a commonly used additive in the tin electroplating industry, was also studied during tin electrodeposition on a boron doped diamond electrode. Figure 9a shows the current transient of tin electrodeposition recorded in the presence of ENSA; an almost complete inhibition of the tin deposition is seen (note that the currents are much lower than in Figure 5). Transients are essentially flat, the absence of $t_{\max }$ and $i_{\max }$ does not allow to compare these results to the standard nucleation and growth model of SH. Furthermore, the SEM image in Figure $9 \mathrm{~b}$ confirms the inhibition of the tin electrodeposition on boron doped diamond electrode in the presence of ENSA. Hardly any tin crystallites (in fact only one) are seen in the micrograph.

\subsection{Comparison to Tin Electrodeposition on Gold and Other Works}

The above results are in partial agreement with our previous work on the effect of naphthalene-based additives on tin electrodeposition on gold. ${ }^{[15]}$ In our previous study, we showed that on gold surfaces, NPT and NPTS lie flat on the surface and interact mainly via van der Waals forces, with NPTS molecules forming a more compact structure due to intermolecular lateral interactions. Thus, one can expect that on BDD, NPT and NPTS might also lie flat, since van der Waals interactions are not very sensitive to the electrode surface. Also, the intermolecular lateral interactions between NPTS molecules are not expected to change significantly on BDD. The results on BDD show that a more compact film formed in the presence of NPTS decreases the nucleation kinetics more than NPT.

With respect to HNPTS, our work on gold showed ${ }^{[15]}$ it does not lie flat on the surface, but rather that the naphthol group 

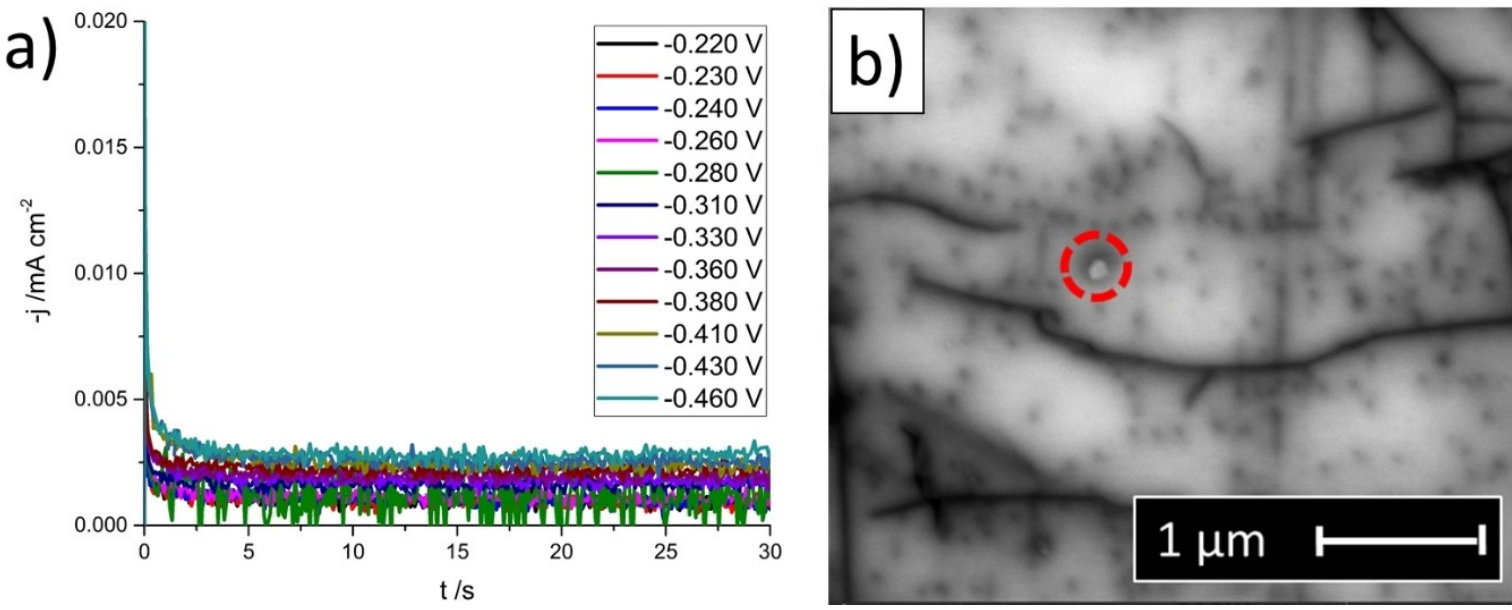

Figure 9. a) Current transients of tin electrodeposition on a boron doped diamond surface in the presence of $1 \mathrm{mM} \mathrm{ENSA}, 0.1 \mathrm{M} \mathrm{H}_{2} \mathrm{SO}_{4}, 0.5 \mathrm{mM} \mathrm{SnSO}_{4}$, recorded between -0.220 to $-0.460 \mathrm{~V}$. b) Scanning electron micrograph of tin electrodeposited on a boron doped diamond surface in $0.1 \mathrm{M} \mathrm{H}_{2} \mathrm{SO}_{4}$ and $0.5 \mathrm{mM} \mathrm{SnSO}_{4}$ and in the presence $1 \mathrm{mM}$ of ENSA. The potential was held at $-0.266 \mathrm{~V}$ for $10 \mathrm{~s}$, subsequently the potential was held at $-0.230 \mathrm{~V}$ during $60 \mathrm{~s}$.

undergoes reductive desulfonation and subsequent polymerization via crosslinked reactions. Since polymerization processes are not highly sensitive to the electrode surface, a polymeric film is likely to form in the presence of HNPTS on BDD. Furthermore, ethoxylated $\alpha$-napthalenesulfonic acid (ENSA) shows equivalent polymer film formation, and indeed tin electrodeposition on BDD is highly inhibited in its presence.

The effect of naphthalene-based additives on the kinetics of tin electrodeposition on boron doped diamond is complementary to our previous work on gold electrodes, ${ }^{[15]}$ giving insights on the way naphthalene-based additives affect the kinetics of tin electrodeposition process. On gold, the nucleation process appeared to be too fast to obtain meaningful transients. In this study, we were able to show that NPT, NPTS and HNPTS mainly have an effect on the nucleation process. Moreover, although the transients in the presence of ethoxylated $\alpha$-napthalenesulfonic acid (ENSA) could not be compared to the standard nucleation and growth model of Scharifker and Hills, ENSA exhibits a very similar behavior to that on gold, i.e., a strong inhibition of the tin electrodeposition process.

Our results compare well to previous results on the effect of additives on the initial stages of tin electrodeposition. Both Torrent-Burgues ${ }^{[17]}$ and Lee et al. ${ }^{[10]}$ (studying tin electrodeposition with gluconate on vitreous carbon and with ENSA on steel, resp.) have shown that additives change the nucleation-andgrowth mode from instantaneous to progressive. In addition, Lee et al. ${ }^{[10]}$ argue that ENSA forms aggregates on steel, thereby affecting the mass transport of tin to the active nucleation sites. Clearly, molecular-level details of how the additives precisely influence nucleation remain unresolved; this would eventually depend on detailed in situ spectroscopic studies on welldefined surfaces.

\section{Conclusions}

The effect of naphthalene (NPT), naphthalenesulfonate (NPTS) and hydroxynaphthalenesulfonate (HNPTS) on the kinetics of tin electrodeposition on a boron doped diamond electrode has been studied by using chronoamperometry and scanning electron microscopy (SEM). The potentiostatic current transients were compared to the standard Scharifker-Hills model, giving estimates for the steady state nucleation rate $\left(A N_{0}\right)$ and the number of nucleation sites $\left(N_{0}\right)$ at different applied potentials and with different additives. In the absence of additives, the nucleation and growth process is shown to transition from progressive to instantaneous with increasingly negative potential. A decrease in the nucleation kinetics of tin deposition on BDD was observed in the presence of naphthalene-based additives: NPT showed the smallest effect on the reduction of the kinetics, followed by NPTS, and the strongest effect was observed in the presence of HNPTS. Comparison to the Scharifker-Hills model shows that the steady-state nucleation rate and the number of nucleation sites exhibit the expected decrease in the presence of the different naphthalene-based additives over the entire studied potential range. Additionally, tin (II) diffusion coefficients were determined by fitting the current transients at longer times to the Cottrell equation, the calculated values of tin (II) diffusion coefficient $\left(D_{\mathrm{Sn}^{2+}}\right)$ giving similar values in the absence and presence of the additives. This observation indicates that tin (II) is not complexed by the additives. Moreover, similar values of tin (II) diffusion coefficients were obtained at low negative potentials, suggesting that also the charge-transfer kinetics itself is not strongly influenced by the presence of the additives. The additives mainly affect the nucleation process, presumably by blocking or reducing access to active sites. Ethoxylated $\alpha$-napthalenesulfonic acid (ENSA) strongly inhibits the tin electrodeposition process, similar to deposition on gold, yielding transients that cannot be analyzed with the Scharifker-Hills model. 


\section{Experimental Section}

Before each measurement, all glassware was stored overnight in a solution of $1 \mathrm{gL}^{-1} \mathrm{KMnO}_{4}$ in $0.5 \mathrm{M} \mathrm{H}_{2} \mathrm{SO}_{4}$. Before use, it was rinsed with water and $30 \%$ hydrogen peroxide solution in order to remove permanganate anions and trace impurities. Glassware was boiled in water five times before starting the experiments. The water used to clean glassware and to prepare solutions was demineralized and ultra-filtrated by a Millipore MilliQ system $(18.2 \mathrm{M} \Omega \mathrm{cm})$. A gold wire was chosen as a counter electrode and a reversible hydrogen electrode (RHE) was used as a reference, but all the potentials are referred to the normal hydrogen electrode (NHE).

Chronoamperometric experiments were performed using a potentiostat VSP-300 (Bio-logic). The electrode potential was corrected for Ohmic drop during the measurements, by using $85 \%$ of the Ohmic resistance measured by electrochemical impedance spectroscopy.

The working electrode was a boron doped diamond disk (BDD) (1 $\mathrm{cm}$ diameter, $1 \mathrm{~mm}$ thick). It was prepared before each experiment by mechanical and electrochemical methods. Firstly, it was polished during 5 minutes with diamond powder $(0.05 \mu \mathrm{m}$ particle size), and subsequently it was transferred to an ultrasound bath, and treated during $10 \mathrm{~min}$ in acetone and another $10 \mathrm{~min}$ in water. After mechanical polishing, the BDD electrode was electropolished by cycling 10 times between -0.74 to $1.56 \mathrm{~V}$ vs. NHE in $0.1 \mathrm{M} \mathrm{H}_{2} \mathrm{SO}_{4}$ solution at $50 \mathrm{mV} \mathrm{s}^{-1}$. A cyclic voltammogram of the BDD surface was recorded in $0.1 \mathrm{M} \mathrm{H}_{2} \mathrm{SO}_{4}$ solution at potentials between -0.74 to $1.56 \mathrm{~V}$ at $50 \mathrm{mV} \mathrm{s}^{-1}$ before starting the measurements in order to check the cleanliness of the electrode surface.

The morphology of tin deposit was observed ex situ by scanning electron microscopy SEM. Micrographs were taken using the model JEOL 820 SEM at $2-10 \mathrm{kV}$. Low voltages were chosen due to the semiconductor nature of BDD electrode.

All solutions were prepared from chemicals with the highest purity commercially available: $\mathrm{H}_{2} \mathrm{SO}_{4}\left(96 \%\right.$ ultrapure, Merck), $\mathrm{SnSO}_{4}(\geq$ $95 \%$, Sigma Aldrich), naphthalene ( $\geq 99 \%$, Sigma Aldrich), 2napthalenesulfonic acid sodium salt ( $99.6 \%$, Sigma Aldrich), 4hydroxy-1-naphthalenesulfonic acid sodium salt ( $\geq 95 \%$, Santa Cruz Biotechnology) and ethoxylated $\alpha$-napthalenesulfonic acid $(73.6 \%$, Pulcra chemicals). In the case of ENSA the main impurities are sulfuric acid with $8.7 \%$, and water with $2.4 \%$, other impurities were not provided by the supplier. $100 \mathrm{~mL}$ of electrolyte solution $0.1 \mathrm{M}$ $\mathrm{H}_{2} \mathrm{SO}_{4}$ and $0.5 \mathrm{mM} \mathrm{SnSO}{ }_{4}$ was prepared by adding $555 \mu \mathrm{L}$ of concentrated $\mathrm{H}_{2} \mathrm{SO}_{4}$, and subsequently $500 \mu \mathrm{L}$ of $0.1 \mathrm{M}$ stock solution of $\mathrm{SnSO}_{4}$ to a $100 \mathrm{~mL}$ volumetric flask, with the volume completed with MilliQ water.

Stock solutions of $0.1 \mathrm{M}$ naphthalene-based additives were prepared as follows: $0.115 \mathrm{~g}$ NPTS, $0.112 \mathrm{~g}$ HNPTS and $0.332 \mathrm{~g}$ of ENSA6 were added to 3 different volumetric flasks of $5 \mathrm{~mL}$. Each solution was prepared using MilliQ water. Volumes of $100 \mu \mathrm{L}, 500 \mu \mathrm{L}$ and $1000 \mu \mathrm{L}$ of the mentioned stock solutions were added to get the $0.1 \mathrm{mM}, 0.5 \mathrm{mM}$ and $1 \mathrm{mM}$ of NPTS, HNPTS and ENSA- 6 to the electrochemical cell containing $100 \mathrm{~mL}$ of $0.1 \mathrm{M} \mathrm{H}_{2} \mathrm{SO}_{4}$ and $0.5 \mathrm{mM}$ $\mathrm{SnSO}_{4}$, previously prepared.

For NPT the solid was finely grounded and added directly in the electrochemical cell containing the $100 \mathrm{~mL}$ of $0.1 \mathrm{M} \mathrm{H}_{2} \mathrm{SO}_{4}$ and $0.5 \mathrm{mM} \mathrm{SnSO}_{4}$. The following NPT amounts were added for $0.1 \mathrm{mM}$ NPT $1.3 \mathrm{mg}$, for $0.5 \mathrm{mM}, 5.11 \mathrm{mg}$ (total NPT mass $6.41 \mathrm{mg}$ ), and for $1 \mathrm{mM}, 6.41 \mathrm{mg}$ (total NPT mass $12.82 \mathrm{mg}$ ).

\section{Acknowledgments}

This research was sponsored by Tata Steel Nederland Technology B.V. through the Materials Innovation Institute M2i and the Technology Foundation TTW, which is the applied science division of the Netherlands Organization for Scientific Research (NWO) and the Technology Programme the Ministry of Economic Affairs of the Netherlands.

\section{Conflict of Interest}

The authors declare no conflict of interest.

Keywords: Electrochemical growth • kinetics • naphthalenebased additives $\cdot$ nucleation $\cdot$ tin electrodeposition

[1] T. Djenizian, I. Hanzu, M. Eyraud, L. Santinacci, Comp. Rendus Chim. 2008, 11, 995-1003.

[2] F. C. Walsh, C. T. J. Low, Surf. Coat. Technol. 2016, 288, 79-94.

[3] S. Wen, J. A. Szpunar, Electrochim. Acta 2005, 50, 2393-2399.

[4] C. Eisenmenger-Sittner, H. Bangert, H. Störi, J. Brenner, P. B. Barna, Surf. Sci. 2001, 489, 161-168.

[5] I. Petersson, E. Ahlberg, J. Electroanal. Chem. 2000, 485, 166-177.

[6] J. Torrent-Burgues, E. Guaus, F. Sanz, J. Appl. Electrochem. 2002, 32, 225230.

[7] S. Bakkali, R. Touir, M. Cherkaoui, M. Ebn Touhami, Surf. Coat. Technol. 2015, 261, 337-343.

[8] C. T. J. Low, F. C. Walsh, J. Electroanal. Chem. 2008, 615, 91-102.

[9] C. T. J. Low, F. C. Walsh, Electrochim. Acta 2008, 53, 5280-5286.

[10] L. N. Bengoa, P. Pary, M. S. Conconi, W. A. Egli, Electrochim. Acta 2017, 256, 211-219.

[11] R. L. Broggi, G. M. De Oliveira, L. L. Barbosa, E. M. J. A. Pallone, I. A. Carlos, J. Appl. Electrochem. 2006, 36, 403-409.

[12] J. H. Van Velzen, C. J. Sluyters-Rehbach, M. Sluysters, Electrochim. Acta $1987,32,815-821$

[13] I. Petersson, E. Ahlberg, J. Electroanal. Chem. 2000, 485, 178-187.

[14] D. Aranzales, J. H. O. J. Wijenberg, M. T. M. Koper, J. Electrochem. Soc. 2019, 166, D283-D289.

[15] D. Aranzales, I. Briliani, I. T. McCrum, J. H. O. J. Wijenberg, A. C. A. de Vooys, M. T. M. Koper, Electrochim. Acta 2021, 368, 137606.

[16] M. E. Hyde, R. Jacobs, R. G. Compton, J. Phys. Chem. B 2002, 106, 1107511080.

[17] O. Enea, B. Riedo, G. Dietler, Nano Lett. 2002, 2, 241-244.

[18] A. O. Simm, X. Ji, C. E. Banks, M. E. Hyde, R. G. Compton, ChemPhysChem 2006, 7, 704-709.

[19] J. Zak, M. Kolodziej-Sadlok, Electrochim. Acta 2000, 45, 2803-2813.

[20] M. Palomar-Pardavé, B. R. Scharifker, E. M. Arce, M. Romero-Romo, Electrochim. Acta 2005, 50, 4736-4745.

[21] X. Huang, Y. Chen, J. Zhou, Z. Zhang, J. Zhang, J. Electroanal. Chem. 2013, 709, 83-92.

[22] L. A. Azpeitia, C. A. Gervasi, A. E. Bolzán, Electrochim. Acta 2019, 298, 400-412.

[23] L. A. Azpeitia, C. A. Gervasi, A. E. Bolzán, Electrochim. Acta 2017, 257, 388-402.

[24] F. Kesri, A. M. Affoune, I. Djaghout, J. Serb. Chem. Soc. 2019, 84, 41-53.

[25] S. Trasatti, J. Electroanal. Chem. Interfacial Electrochem. 1972, 39, 163184.

[26] J. K. Nørskov, T. Bligaard, A. Logadottir, J. R. Kitchin, J. G. Chen, S. Pandelov, U. Stimming, J. Electrochem. Soc. 2005, 152, J23.

[27] A. Milchev, ELECTROCRYSTALLIZATION Fundamentals of Nucleation and Growth, Kluwer Academic Publishers, New York, Boston, Dordrecht, London, Moscow, 2002.

[28] B. Scharifker, G. Hills, Electrochim. Acta 1982, 28, 879-889.

[29] G. Scherb, D. M. Kolb, J. Electroanal. Chem. 1995, 396, 151-159.

[30] Y. I. Yanson, How Additives Affect Cu Electrodeposition an Electrochemical STM Study, Leiden University, 2012.

[31] B. R. Scharifker, J. Mostany, J. Electroanal. Chem. 1984, 177, 13-23. 
[32] M. Sluyters-Rehbach, J. H. O. J. Wijenberg, E. Bosco, J. H. Sluyters, J. Electroanal. Chem. 1987, 236, 1-20.

[33] S. Fletcher, J. Cryst. Growth 1983, 62, 505-512.

[34] A. Milchev, J. Electroanal. Chem. 2008, 612, 42-46.

[35] A. Radisic, P. M. Vereecken, J. B. Hannon, P. C. Searson, F. M. Ross, Nano Lett. 2006, 6, 238-242.

[36] E. Gómez, E. Guaus, F. Sanz, E. Vallés, J. Electroanal. Chem. 1999, 465, 63-71.
[37] A. Milchev, J. Electroanal. Chem. 1998, 457, 35-46.

[38] A. Milchev, S. Stoyanov, R. Kaischev, Thin Solid Films 1974, 22, 255-265.

[39] F. J. Barry, V. J. Cunnane, J. Electroanal. Chem. 2002, 537, 151-163.

Manuscript received: January 9, 2021

Revised manuscript received: May 3, 2021

Accepted manuscript online: May 6, 2021 